\title{
Editorial note to the article by Onizuka et al.: Lidocaine depolarizes the mitochondrial membrane potential by intracellular alkalization in rat dorsal root ganglion neurons
}

\author{
Koh Shingu
}

Published online: 4 March 2011

(C) Japanese Society of Anesthesiologists 2011

The editorial board of the Journal of Anesthesia has determined that the content of the article entitled "Lidocaine depolarizes the mitochondrial membrane potential by intracellular alkalization in rat dorsal root ganglion neurons," published in 2011 in the Journal of Anesthesia
(J Anesth. 2011. doi:10.1007/s00540-010-1079-y), differs significantly from that of an article with a similar title published in 2010 in Anesthesia \& Analgesia (Anesth Analg. 2010;111:775-83). 